\title{
Seismic Response Prediction of Buildings with Base Isolation Using Advanced Soft Computing Approaches
}

\author{
Mosbeh R. Kaloop ${ }^{1,2,3}$ and Jong Wan $\mathrm{Hu}^{1,2}$ \\ ${ }^{1}$ Department of Civil and Environmental Engineering, Incheon National University, Incheon 22012, Republic of Korea \\ ${ }^{2}$ Incheon Disaster Prevention Research Center, Incheon National University, Incheon 22012, Republic of Korea \\ ${ }^{3}$ Department of Public Works and Civil Engineering, Mansoura University, Mansoura 35516, Egypt \\ Correspondence should be addressed to Jong Wan Hu; jongp24@incheon.ac.kr
}

Received 15 November 2016; Revised 14 February 2017; Accepted 14 February 2017; Published 2 March 2017

Academic Editor: Angela De Bonis

Copyright (C) 2017 Mosbeh R. Kaloop and Jong Wan Hu. This is an open access article distributed under the Creative Commons Attribution License, which permits unrestricted use, distribution, and reproduction in any medium, provided the original work is properly cited.

\begin{abstract}
Modeling response of structures under seismic loads is an important factor in Civil Engineering as it crucially affects the design and management of structures, especially for the high-risk areas. In this study, novel applications of advanced soft computing techniques are utilized for predicting the behavior of centrically braced frame (CBF) buildings with lead-rubber bearing (LRB) isolation system under ground motion effects. These techniques include least square support vector machine (LSSVM), wavelet neural networks (WNN), and adaptive neurofuzzy inference system (ANFIS) along with wavelet denoising. The simulation of a 2D frame model and eight ground motions are considered in this study to evaluate the prediction models. The comparison results indicate that the least square support vector machine is superior to other techniques in estimating the behavior of smart structures.
\end{abstract}

\section{Introduction}

Nowadays, smart structures are used widely to reduce and control the dynamic loads effects and structures response, respectively [1,2]. Structures built on lead-rubber bearing (LRB) isolations are ones of high effectiveness of structure control system [1-3], but the application of this system is still limited to use in real construction cases. Moreover, the LRB is more effective in controlling steel and reinforced concrete buildings under seismic loads $[1,4]$. However, responses of structures with base isolation under seismic loads should be modeled to predict their behavior under the changes of seismic loads effects. Despite the responses of passive and active controller structures being modeled before $[5,6]$, this study presents the modeling prediction systems for a building with base isolation as a first application for this type of smart structures. Therefore, the response prediction of structures with base isolation is the main aim of this study.

The dynamic response of structures with base isolation is studied in time and frequency domains previously for the steel and reinforced concrete structures $[2,7]$. In addition, the design model of LRB is presented in [1], and the advantages and disadvantages of this system are presented in $[2,8]$. The LRB model used in this study is designed based on a maximum vertical load of $15630 \mathrm{KN}$ and the allowable lateral displacement of $400 \mathrm{~mm}$ [1]. In general, as any controlled structure, the response of structures under seismic loads contains three components of movements: static, semistatic, and dynamic [9-11]. The dynamic response of structures is highly impacted in the seismic time effects and the periodically dynamic effects are affected by collapse of structures, so this study is focused on the dynamic behavior of structures. A nonlinear component of steel structure is simulated to study the behavior of centrically braced frame (CBF) steel building subjected to earthquake loading by using the OpenSees [12]. Moreover, this study is limited for the simulation of full scale control system.

Applications of soft computing modeling of the response of controlled structures are still limited, and the CBF with LRB isolation system is not previously studied. Therefore, this study aims to develop a prediction model (PM) that can be used to detect the behavior of these types of structures. The 
advanced PMs are support vector machine (SVM), neural networks (NN), and neurofuzzy (NF) [5, 6, 13-15]. The wavelet is linked with $\mathrm{NN}$ and NF to improve the responses of these techniques $[6,16]$. The NN and NF methods are used for modeling the performance of the controller structures; however there is no study implementing the SVM in predicting the behavior of controller structures. Furthermore, the model design is divided into two models that are inputoutput and output-only models. In this study, the inputoutput system is utilized [17]. The input parameters (seismic effects and response of structures) are evaluated previously by $[5,6,14]$ and it is found that the seismic loads with time delay response output are good parameters that can be used to predict the nonlinear behavior of controlled structures. One and two time delays for the response of controlled structures are studied and it is found that the two-time delayed input parameters are more influential on the performance of model $[6,14,18]$. In this study, novel PMs are investigated. The twodelayed responses of structure are considered with seismic loads effects and the wavelet denoising is applied.

Finally, this study aims to develop new models that can be used to detect the behavior of controlled structures using LRB system. Three advanced soft computing techniques are utilized. A simulation building is designed using OpenSees program and subjected to nonlinear dynamic loads based on Los Anglos (LA) ground motion (GM) to predict the high response of the building. This paper is organized as follows: Section 2 discusses the methodology and evaluation theories such as the strategy used to investigate the performance of the identification models. Section 3 contains the simulation and GM's process and collection data, as well as the measurements preanalysis. The modeling results and discussions for the training and testing stages are given in Section 4. The conclusions are summarized in Section 5.

\section{Models Overview and Design}

In this study, three advanced models are used after input data filtration using discrete wavelet transforms (DWT) to remove the noise. The Daubechies wavelet for low frequency decomposition utilized to denoise the response data which is used as inputs to the models. To compare the results with previous studies $[5,6,15]$, two levels of DWT are applied to train the responses of smart structures. The DWT is described in $[6,14]$; however, this section is dedicated to summarize the models used.

The least square support vector machine (LSSVM), wavelet neural networks (WNN), and adaptive neurofuzzy inference system (ANFIS) are highly advanced models that can be used to detect the response of structures, environmental effects, and so forth $[13,14,16,19]$. Based on previous studies $[5,6,14,15,18]$, time-delayed models are good to predict the behavior of smart structures. It has been reported that the two-time delayed models are better than one-time delayed [18]. Accordingly, in this study a two-time delayed model is applied.

2.1. Least Square Support Vector Machine (LSSVM). Suykens and Vandewalle [20] proposed a modified version of support vector machine (SVM) classifiers, Least Squares SVM (LSSVM) classifiers. The LSSVM model uses regression technique based on statistical learning theory [13]. It considers a Gaussian process and regularization network to design a relation between the input and output data $[13,20,21]$. Consider a given training of $N$ data points with input $\left(x_{i} \in\right.$ $\left.R^{N}\right)$ and output $\left(y_{i} \in r\right)$ data, where $R^{N}$ and $r$ are $N$ and one-dimensional vectors space for the input and output data, respectively. In this study, the input parameters are the seismic loads and time delay of the structures response and the output is the prediction of the structure response. The LSSVM models for the nonlinear modeling take the following form:

$$
y(x)=w^{T} \varphi(x)+b,
$$

where is the $\varphi(x)$ is a nonlinear map function between the input and output data. $w$ is an adjustable weight vector, $w \in$ $R^{N} ; b$ is a scalar threshold, $b \in r$. To extract the map function estimation, the minimization principal is used firstly by penalizing a regression error as follows $[22,23]$ :

$$
J(w, e)=\frac{1}{2} w^{T} w+\gamma \frac{1}{2} \sum_{i=1}^{N} e_{i}^{2}
$$

such that

$$
y_{i}=w^{T} \varphi\left(x_{i}\right)+b+e_{i}, \quad i=1,2, \ldots, N,
$$

where $\gamma$ is the regularization parameter and $e_{i}$ is the model errors.

Secondly, the Lagrange multipliers method is applied to solve the optimization problem in (2) as follows [22]:

$$
\begin{aligned}
L(w, b, e, \alpha)= & J(w, e) \\
& -\sum_{i=1}^{N} \alpha_{i}\left\{w^{T} \varphi\left(x_{i}\right)+b+e_{i}-y_{i}\right\},
\end{aligned}
$$

where $\alpha_{i}$ is the Lagrange multiplier. By solving the above optimization $[20,21]$, the prediction values of the response of structure $(\hat{y}(\cdot))$ can be presented as follows:

$$
\widehat{y}(x)=\sum_{i=1}^{N} \alpha_{i} K\left(x, x_{i}\right)+b,
$$

where $K$ is the radial basis function (RBF).

The RBF is used in this study is given by

$$
\begin{aligned}
& K\left(x_{i}, x_{l}\right)=\exp \left\{-\frac{\left[x_{i}-x_{l}\right]^{T}\left[x_{i}-x_{l}\right]}{2 \sigma^{2}}\right\}, \\
& i, l=1,2, \ldots, N,
\end{aligned}
$$

where $\sigma$ is the width of RBF.

2.2. Wavelet Neural Networks (WNN). The wavelet neural network (WNN) or WAVNet is used to detect the dynamic behavior of systems [24]. The architecture for a WNN is the 
same as for a NN with wavelet neuron $[16,25]$. A WNN is a model that connects the $\mathrm{NN}$ with wavelet decomposition that leads to a nonlinear wavelet function. In this study, the structure behavior prediction model is designed using WNN model with an output $(\widehat{y})$ computed as follows:

$$
\widehat{y}_{k}=\sum_{i=1}^{N} c_{k-i} \psi\left(a_{i}\left(x_{k-i}-b_{i}\right)\right)+w
$$

where $c_{k-i} ; a_{i}$; and $b_{i}$ are coefficient, dilation, and translation variables, respectively; $x_{k-i}$ are the input data; and $\psi$ is a wavelet function. The WNN consists of an input vectors, layer of weighted wavelets, and output vector. The WNN parameters can be calculated by a backpropagation-learning method [25]. The WNN training objective is to minimize the output error of the model.

The selection of wavelet function depends on the application used $[16,25]$. There are many wavelet functions that can be used. In this study, the Mexican hat wavelet function is used to implement the proposed nonlinear smart structure behavior model. The wavelet function for any variable $(x)$ can be presented as follows:

$$
\psi(x)=\left(\|x\|^{2}-p\right) e^{-\|x\|^{2} / 2},
$$

where $p$ is the model order. The Mexican hat wavelet function is successfully applied in WNN modeling by many authors to predict different cases of structures behavior and modeling the environmental effects $[16,19,24,25]$; however it is selected in this study.

2.3. Adaptive Neurofuzzy Inference System (ANFIS). The adaptive neurofuzzy inference system (ANFIS) is used previously to predict the behavior of smart structures and it was found that this method is suitable to identify the displacement and acceleration measurement of structures response with passive or active controller systems $[5,6,18]$. The ANFIS model is introduced by Jang [26], and it has been applied on different case studies [14, 15, 27, 28]. The process of ANFIS model is presented in [18]. The hybrid learning rule is used to estimate the ANFIS parameters based on back propagation gradient and least square methods [28]. The Mamdani and Sugeno are the two approaches for fuzzy inference system [29]. The differences between the two approaches arise from the consequent part where Mamdani's approach uses fuzzy membership functions, while linear or constant functions are used in Sugeno's approach. The neurofuzzy model used in this study implements the Sugeno's fuzzy approach with seismic and time delay for the response of structure as input variables and response of structure as output variable.

2.4. Models Process and Evaluation. Based on the previous studies $[5,14,16,18,21,25,27,29,30]$, the three models can be used to predict the nonlinear behavior of structures. In addition, it is worth noting that no studies have implemented the three models in predicting the behavior of smart structures based on base isolation system. Herein, the proposed model for the behavior of the simulation of smart building (centrically braced frame (CBF) steel building with LRB isolator system) was processed over five stages as shown in Figure 1. The process of these five stages was performed through (1) design of the simulation model and response measurement under GM, (2) denoising of the GM signal and response measurements using wavelet denoising, (3) prediction stage, (4) comparison and selection of the best model that can be used in our case, and (5) validation and evaluation of the model selection for the structure behavior under different GM cases. In the first stage, the simulation design model is introduced, evaluated, and developed by Incheon Disaster Prevention Research Center (IDPRC) (see $[1,31-33])$ and the response of building is obtained by OpenSees code design; in addition, the real GM is considered in this stage (see Section 3). In the second and third stages, a novel prediction modeling was developed with wavelet denoising for the behavior of CBF steel building based on LRB isolator system. Then in the fourth stages, a comparison was made between the developed models for prediction of the structure behavior. Finally, the selected model is evaluated using different cases of GM's (see Section 3).

In the comparison and validation stages, five statistical evaluation criteria are used to assess the models performances; $\left(J_{1}\right)$ is the correlation coefficient $\left(R^{2}\right)$ :

$$
J_{1}=R^{2}=\left(\frac{\sum_{i=1}^{n}\left(y_{i}-y_{m}\right)\left(\widehat{y}_{i}-\widehat{y}_{m}\right)}{\sum_{i=1}^{n}\left(y_{i}-y_{m}\right)^{2} \sum_{i=1}^{n}\left(\widehat{y}_{i}-\widehat{y}_{m}\right)^{2}}\right)^{2},
$$

where $y_{i}$ and $\hat{y}_{i}$ denote the measured and predicted structure behavior, respectively, $n$ is the number of time steps, and $y_{m}$ and $\widehat{y}_{m}$ represent the mean of measured and predicted values, respectively. $J_{1}$ provides information for linear dependence between measured and predicted values. Therefore, $J_{2}$ and $J_{3}$ are mean absolute error (MAE) and root mean-square error (RMSE), respectively; $J_{2}$ and $J_{3}$ measure a linear scouring rule and describes the average magnitude of the errors by giving more weight to large errors to evaluate the performance of the models.

$$
\begin{aligned}
& J_{2}=\text { MAE }=\frac{\sum_{i=1}^{n} \mathrm{abs}\left(y_{i}-\widehat{y}_{i}\right)}{n} \\
& J_{3}=\mathrm{RMSE}=\sqrt{\frac{\sum_{i=1}^{n}\left(y_{i}-\widehat{y}_{i}\right)^{2}}{n} .}
\end{aligned}
$$

In addition, the 4 th evaluation criteria $\left(J_{4}\right)$ is the fitting rate (FR) which proposes the same responses as the measured data; $J_{4}$ becomes 100 .

$$
J_{4}=\left[1-\frac{\operatorname{var}(y-\widehat{y})}{\operatorname{var}\left(y-y_{m}\right)}\right] \times 100,
$$

where var is the variance of data. Finally $J_{5}$ is the autocorrelation function (ACF) of the model residuals. The lag $m$ autocorrelation (AC) is defined as follows:

$$
\lambda(m)=\frac{1}{n} \sum_{i=1}^{n} e(i-m) e(t),
$$

where $e$ is the model error, and, therefore, $\mathrm{AC} \lambda(m)$ is zero when the parameters of the model are nonzero. A large AC 


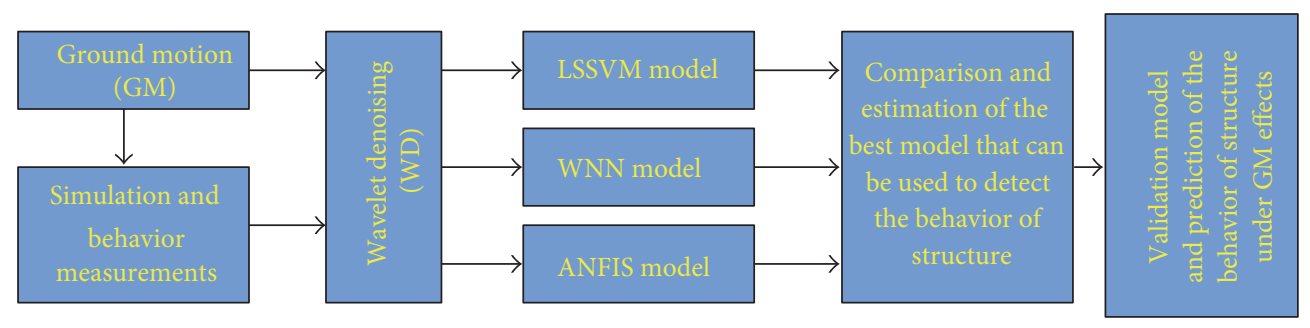

FIGURE 1: Models process.

TABLE 1: GMs' properties and statistical structures response.

\begin{tabular}{|c|c|c|c|c|c|c|c|c|}
\hline \multirow{2}{*}{\multicolumn{2}{|c|}{ GM record }} & \multicolumn{5}{|c|}{ Ground motion properties } & \multicolumn{2}{|c|}{ Roof Response } \\
\hline & & \multirow{2}{*}{$\begin{array}{l}\text { R.S. } \\
6.5\end{array}$} & \multirow{2}{*}{$\frac{\text { Distance }(\mathrm{Km})}{4.1}$} & \multirow{2}{*}{$\frac{\text { Duration (sec.) }}{39}$} & \multirow{2}{*}{$\frac{\text { Max PGA }(\mathrm{g})}{0.49}$} & \multirow{2}{*}{$\frac{\text { Max Sa }(\mathrm{g})}{1.54}$} & \multirow{2}{*}{$\begin{array}{c}\text { Max Disp }(\mathrm{mm}) \\
117.98\end{array}$} & \multirow{2}{*}{$\frac{\operatorname{Max} \operatorname{Acc}(\mathrm{g})}{0.54}$} \\
\hline LA4 & 1979 El Centro (Imperial Valley) & & & & & & & \\
\hline LA8 & 1992 Barstow (Landers) & 7.3 & 36 & 80 & 0.43 & 1.01 & 165.83 & 0.53 \\
\hline LA13 & 1994 Newhall (Northridge) & 6.7 & 6.7 & 60 & 0.68 & 2.48 & 275.47 & 1.04 \\
\hline LA20 & 1986 North Palm Springs & 6 & 6.7 & 60 & 0.99 & 3.85 & 322.80 & 1.22 \\
\hline LA23 & 1989 Loma Prieta & 7 & 3.5 & 25 & 0.42 & 1.64 & 211.66 & 0.73 \\
\hline LA27 & 1994 Northridge & 6.7 & 6.7 & 60 & 0.93 & 1.85 & 325.79 & 0.82 \\
\hline LA30 & 1974 Tabas & 7.4 & 1.2 & 50 & 0.99 & 3.72 & 275.53 & 1.12 \\
\hline LA40 & Palos Verdes (simulated) & 7.1 & 1.5 & 60 & 0.63 & 1.38 & 588.38 & 0.95 \\
\hline
\end{tabular}

indicates that the structure is not relevant to the system or that there might be a need to increase the model order. In real application, $\mathrm{AC} \lambda(\mathrm{m})$ cannot be zero when $\mathrm{m}$ is nonzero because of limited length of observation points. If the value of AC falls within $95 \%$ of the confidence interval, the AC value is insignificant and this value is considered to be equal to zero [16].

\section{Ground Motions and Building Design}

Eight GMs were investigated in this paper. The characteristics of the GMs and the response of the structure are presented in Table 1. One GM (LA40) and its response were implemented to compare the three models and the seven GMs and the building responses data were used to validate the developed best model. The building description and GMs' characteristics are described below.

Real Los Anglos (LA), USA, GMs are applied with different probabilities for more than 50 years. Four GMs (LA $04,08,13$, and 20 ) were with probability $10 \%$ and the remaining GMs (LA 23, 27, 30, and 40) with probability $2 \%$ [32]. Figures 2 and 3 and Table 1 represent the recorded GMs' signals and properties. Figure 3 illustrates the acceleration response spectrum of the applied GMs' recorded signals.

From Figures 2 and 3 and Table 1, it is seen that the peak ground acceleration (PGA) is observed in GM's LA 20 and 30. Also, the maximum spectral acceleration ( $\mathrm{Sa}$ ) is occurred with GM LA20. Moreover, the long period duration of motion is occurred with GMs LA 30 and 40. The maximum of mean $\mathrm{Sa}$ is $1.67 \mathrm{~g}$ and the mean response is close to the GM LA 27 response.
A finite element model is designed through OpenSEES program with an intention to perform nonlinear dynamic time-history analysis $[30,31]$. The prototype frame buildings were constructed to satisfy design limits under the designbased earthquake (DBE) level. The 2D nonlinear pushover analyses with equivalent lateral loads were conducted to verify the adequacy of initial frame design. The simulation design CBF steel building with LRB isolator system is presented in Figure 4. The building presented in this study was constructed as 9-story and 5-span structures with perimeter moment-resisting CBFs to sustainably withstand lateral loads (e.g., wind and earthquake loads). They were designed under essentially regular condition without inplane torsional effect, owing to symmetrical plan with masses and stiffness uniformly distributed. A plan view of 9-story square buildings with five $9.14 \mathrm{~m}$ bays is shown in Figure 4(a). Three braced frame bays presented in the Figure 4(b) were installed on each side. The elevation view of the perimeter moment-resisting frame is shown in Figure 4(b). The inverted $\mathrm{V}$-braced frame systems were accepted for frame design among various types of $\mathrm{CBF}$ systems. The first story height is $5.49 \mathrm{~m}$ and 8 stories of the CBF buildings have $3.96 \mathrm{~m}$ story height. The column sections were designed with the uniform sizes throughout all stories while beam sections assigned to the higher stories were designed with smaller beam sizes (i.e., W $24 \times 62$ beam size in the 9 th story). The sizes of brace, beam, and column members were designed in accordance with the AISC-LRFD steel design manual [34]. The details for bracing, columns, and distribution of beam sections to frame design are presented in Figure 4(b). Moreover; reinforced sections were built as shown in Figure 4(b) with simple pinned 

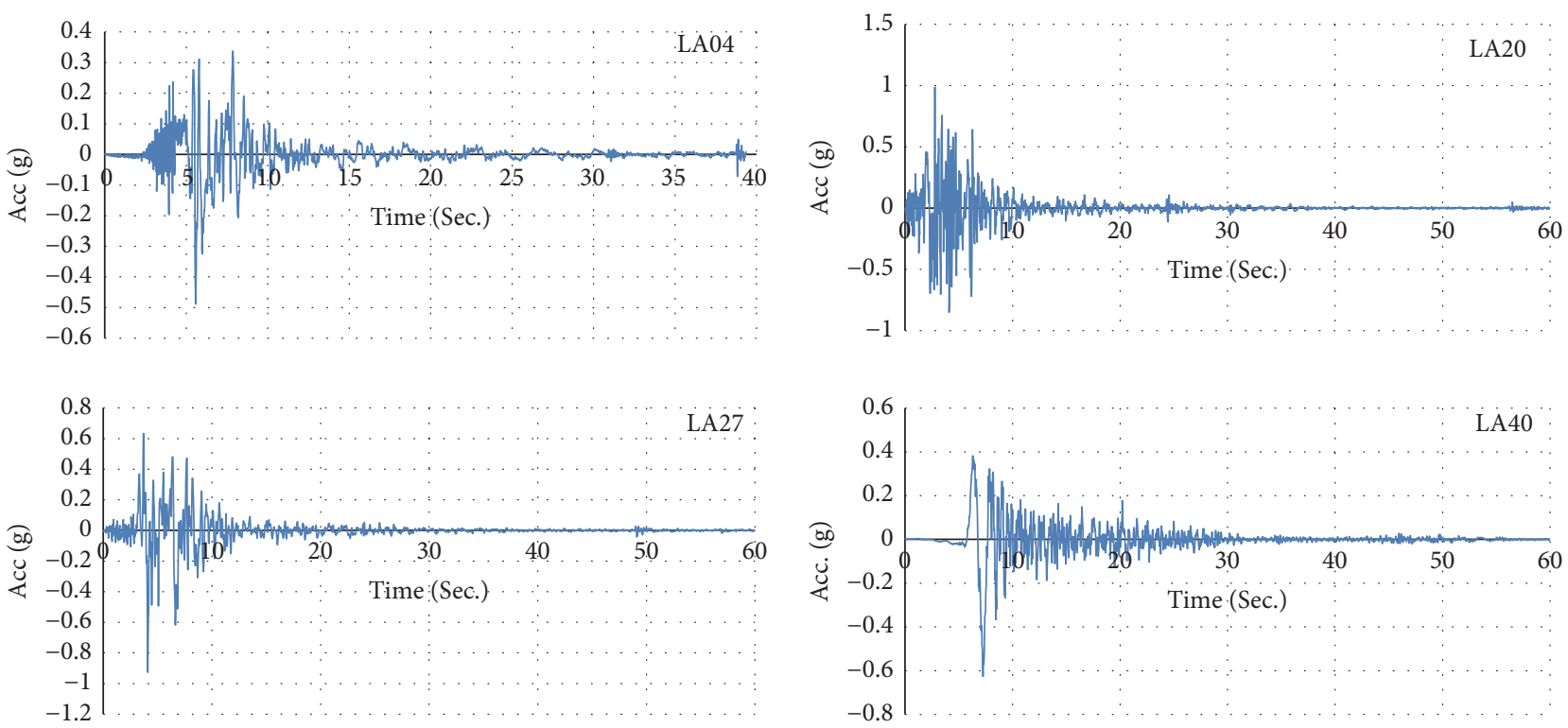

FIGURE 2: GMs' recorded signals for the training and testing stages.

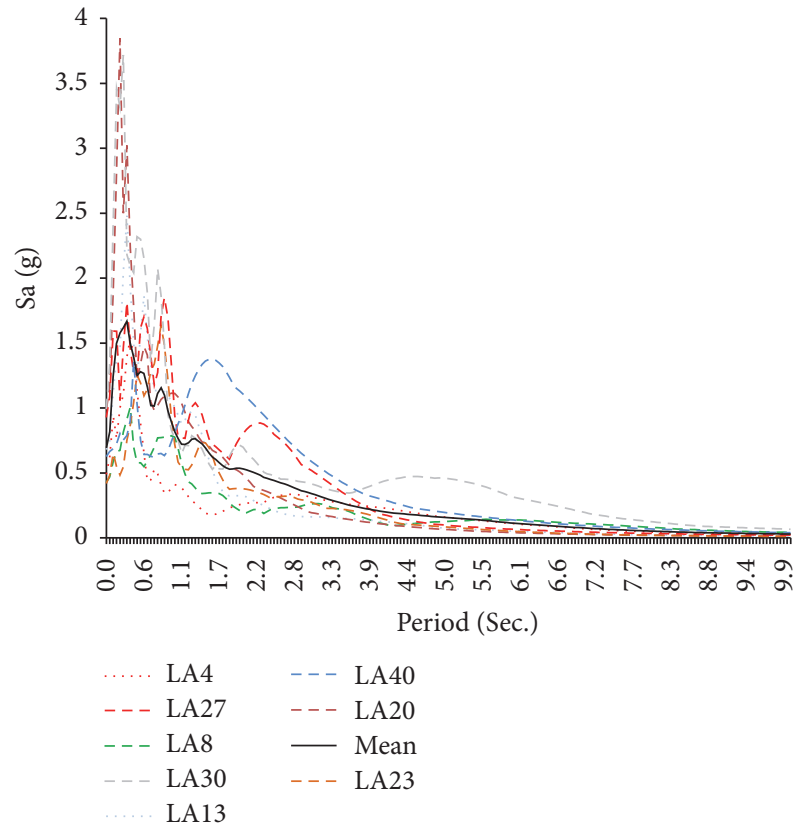

FIgURE 3: Acceleration response spectrum for the selection of GMs' signals.

connections only at first three stories withstanding shear force. Furthermore, the base isolation property is presented in $[1,33]$.

Figure 5 and Table 1 represent the response of the building floor (acceleration and displacement). In addition, the figure presents the effects of wavelet denoise. The frequency content of the roof behavior is presented in Figure 5(c), where the fast Fourier transformation (FFT) is used to extract the frequency contents of roof response.
The maximum absolute displacement is observed with GM LA 40, while the maximum absolute acceleration response is occurred with LA20. The wavelet denoising effect is shown clearly in the figures. The average maximum of absolute acceleration measurement is decreased by $11.7 \%$, as shown in Figure 5(c). The accuracy of measurements is increased when the noises are removed as presented in Figure 5(b) after 24.5 second. It is, also, observed that there are no information losses in the GM effect period. However the wavelet denoise is suitable to use in this case. The fundamental frequency contents of the response of the simulation building are $0.9,0.75,0.75,0.75,0.8,0.7,0.85$, and 0.7 for the LA4, 8, 13, 20, 23, 27, 30, and 40, respectively. In addition, it can be seen that the maximum amplitude is occurred with GM LA 27, while the maximum frequency band is observed with GM LA 40.

The GM LA40 motion is most suitable to design a prediction model, where the maximum response and maximum period occurred with this GM. The maximum acceleration response variation is $0.27 \mathrm{~g}$ from the GM LA20 and, also, it can be seen that the Richter scale (RS) is high; and the distance $(1.5 \mathrm{Km})$ is small. Moreover, it can be seen that the noise effectiveness of this GM is lower than other GMs.

\section{Results and Discussions}

The prediction models presented in Section 2 are used in this part to identify the best model that can be used after denoising the signal measurements. The ANFIS model with wavelet is used previously by Arsava et al. [5] and Mitchell et al. [6] and they found that this model can be used to predict the behavior of controlled structures. Kaloop et al. [18] compared this model without wavelet and Nonlinear AutoRegresive with eXogenous inputs and found that the two models can be used to detect the behavior of controlled 


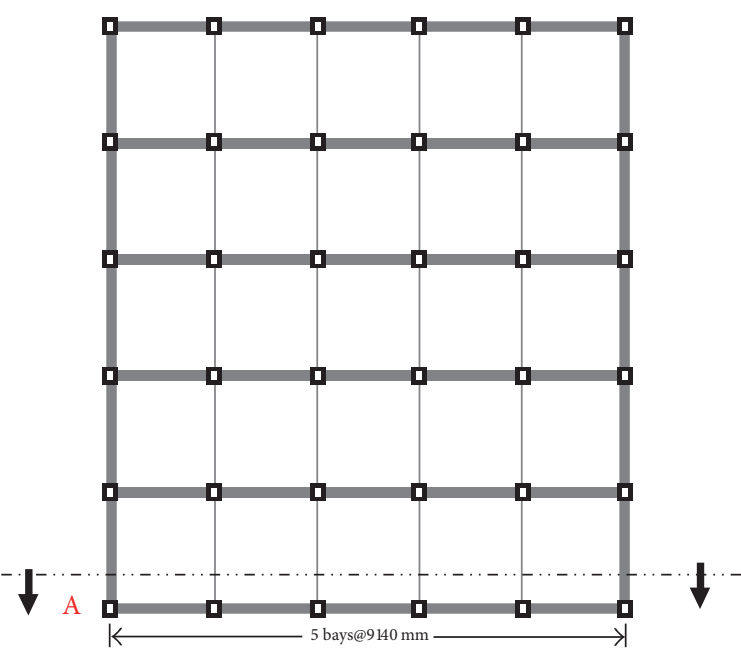

(a)
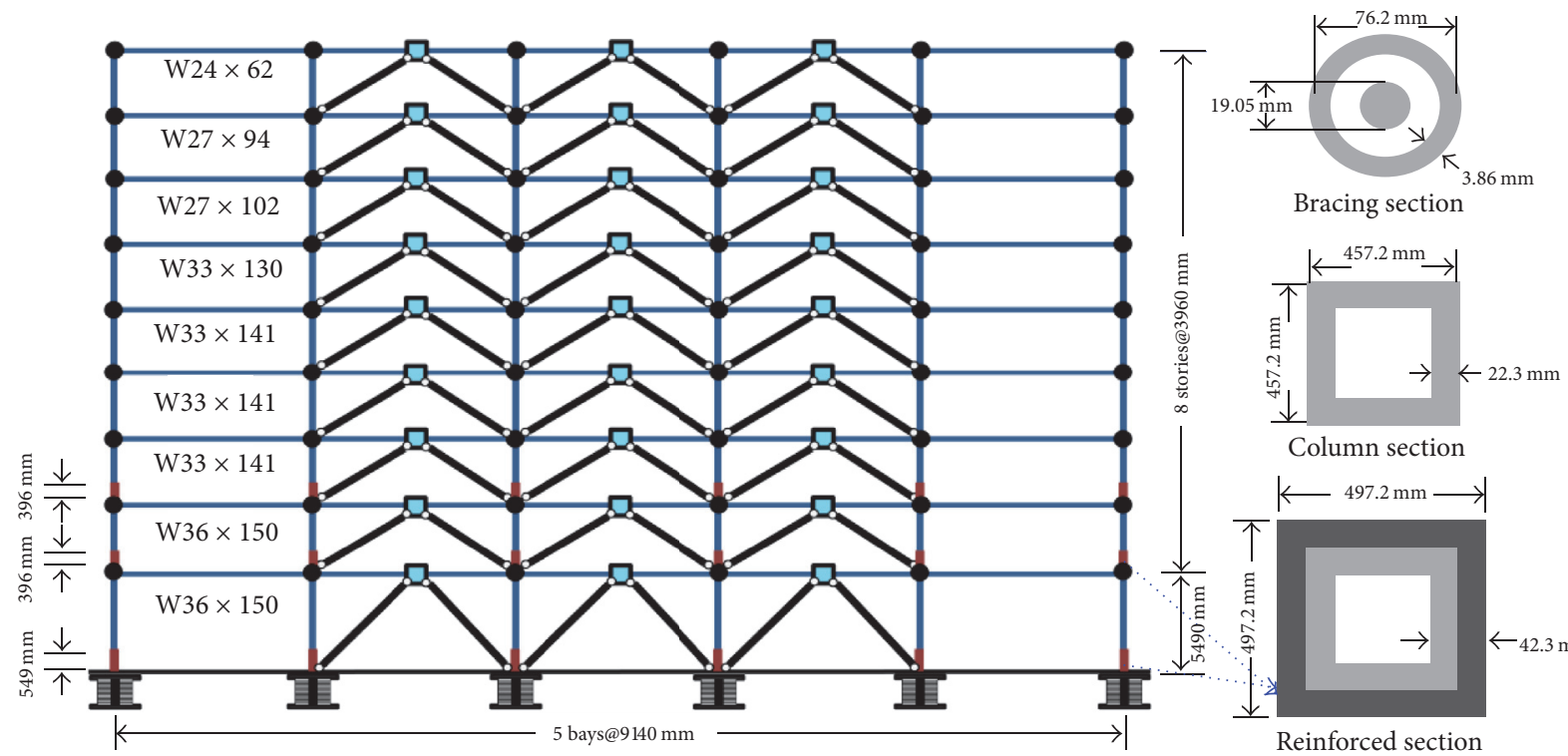

Column section

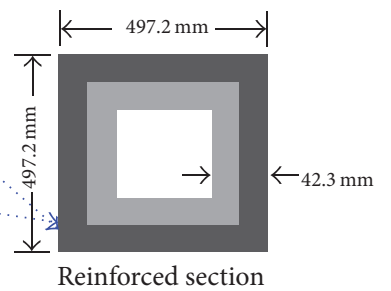

(b)

FIGURE 4: A nine-story building employing an LRB isolator system with LRB isolation system (a) building plan and (b) elevation view of section $\mathrm{A}$ and sections details.

TABLE 2: Statistical analysis of the development models.

\begin{tabular}{lcccc}
\hline Method & $J 1$ & $J 2(\mathrm{~g})$ & $J 3(\mathrm{~g})$ & $J 4(\%)$ \\
\hline LSSVM & 0.99 & $2.14 e-6$ & $6.50 e-6$ & 99.99 \\
WNN & 0.99 & $6.51 e-3$ & $1.08 e-2$ & 99.41 \\
ANFIS & 0.99 & $8.11 e-6$ & $1.85 e-5$ & 99.99 \\
\hline
\end{tabular}

structures. In this study, the wavelet is used first to denoise the signals and then applying the models, as shown in Figure 1. The GM LA 40 is used and its response to design the three models with two-delayed input for the building response.

Table 2 and Figure 6 illustrate the comparison between the training stage of the model design. Moreover, Figure 7 represents the observation and prediction of building behavior using the three models.
For the LSSVM, prediction model has three inputs and one output. The GM, one-delayed for the building response and two-delayed for the building response after wavelet denoising parameters form up the input variables of model and the building response is the output variable. The noise part is removed from the data used in the model design, which is applied in the training stage. GM and Building response are presented in Figure 2(LA40) and 5(b), respectively. LSSVM application for the training and testing analysis is carried using MATLAB. To improve the LSSVM estimation process, the selection model parameters are reasonably important. In this study, the RBF is used to perform the model. The proper choice of set for $\gamma$ and $\sigma$ is a vital task in achieving a highly successful estimation of LSSVM [13, 23]. The trial and error technique is used to determine the model parameters values of $\alpha, b, \gamma$, and $\sigma$. 


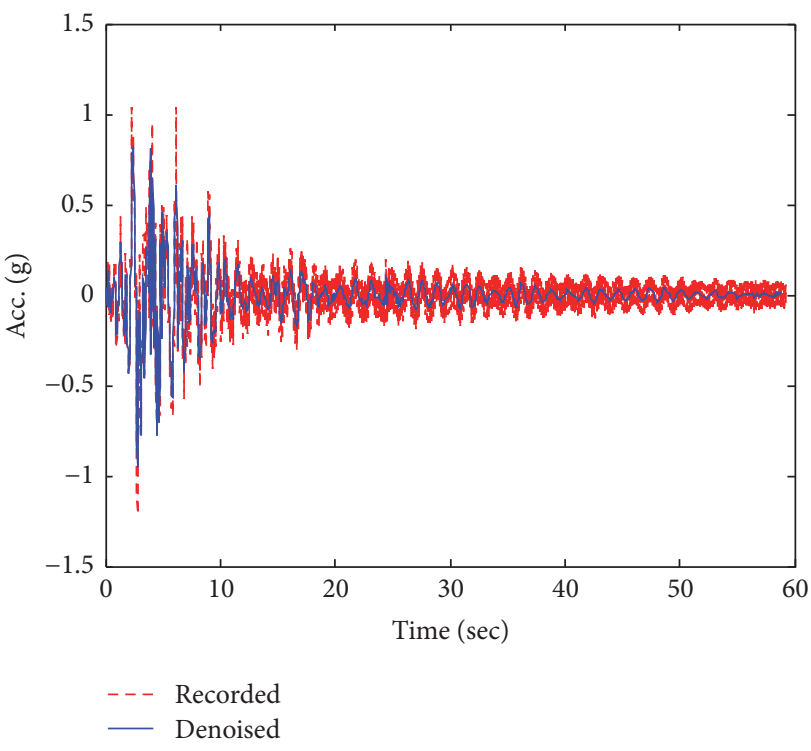

(a)

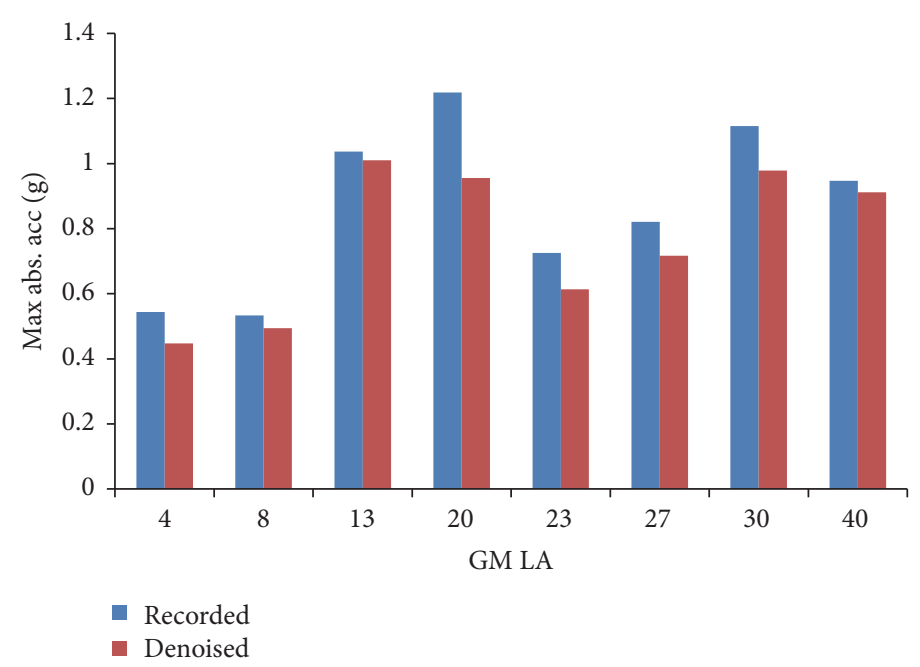

(c)

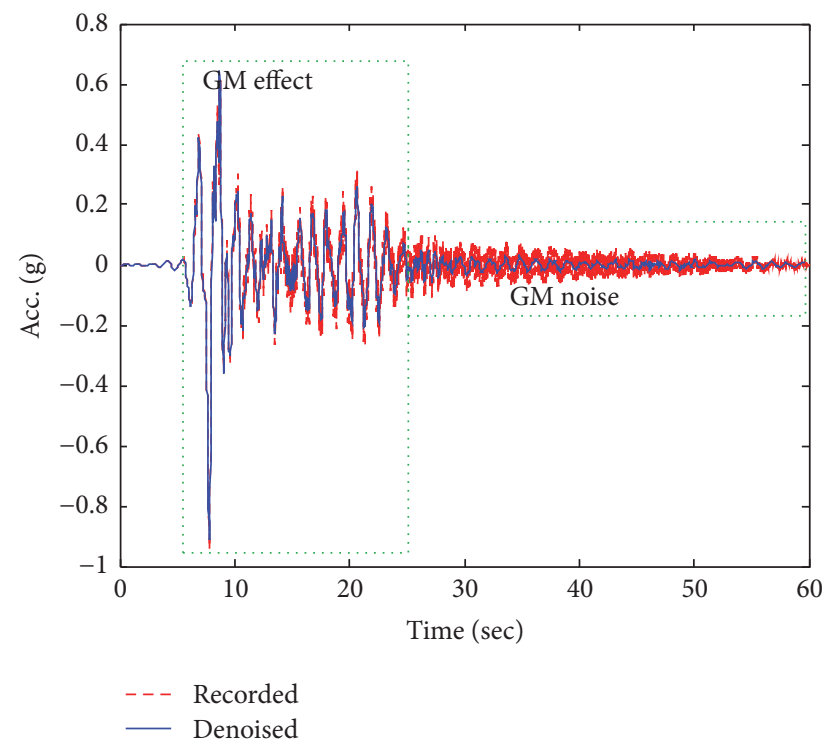

(b)

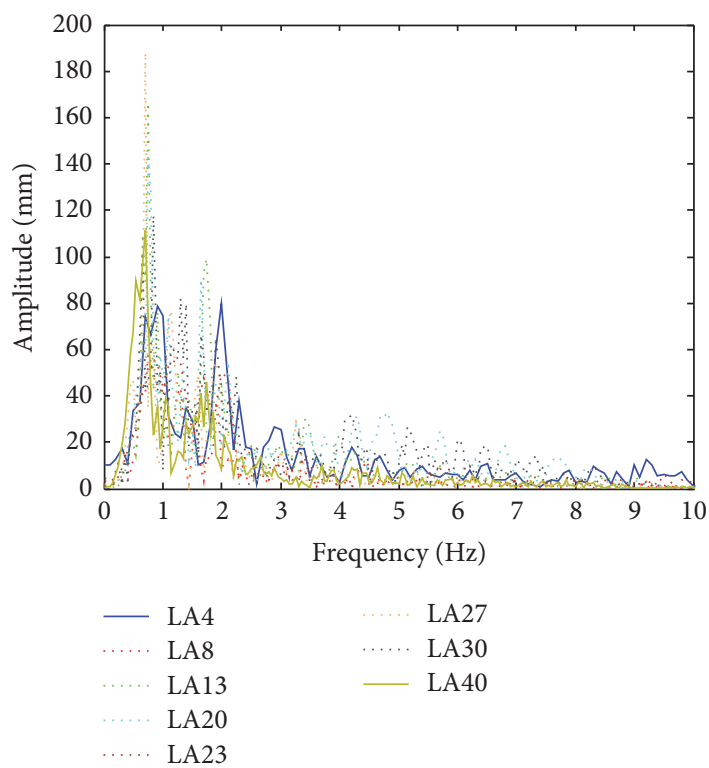

(d)

FIGURE 5: Structure response in time domain for the LA (a) 20, (b) 40, and (c) maximum acceleration response before and after denoising and $(\mathrm{d})$ in frequency domains.

The SVM Toolbox in MATLAB is used to detect the model parameters. Figure 8(a) illustrates a RMSE for the selected trail used for the prediction of the building response; the figure shows the RMSE of 12 trail iterations of the training dataset to optimize the $\gamma$ and $\sigma$ values. In this case, the lowest RMSE was utilized to estimate the optimum $\gamma$ and $\sigma$ values. In addition, Figure 8(b) shows the values of $\alpha$ for the prediction model selection which is calculated based on the optimized selection of $\gamma$ and $\sigma$ values. From Figure 8(a), it can be shown that the model parameter values are optimized with $\gamma=8.39 e 6$, and $\sigma=13.45$. Moreover, it can be seen that the model is improved after only three iterations.
Furthermore, the $b$ value is calculated $(b=-0.6812)$. Therefore, the optimization and calculation values of the model parameters are used in this study to identify the behavior of building.

Figure 7(a) illustrates the performance of the LSSVM model for the training set. It, also, shows from Table 2 that the values of $J 1$ and $J 4$ are very close to 1 and $100 \%$, respectively, while the values of $J 2$ and $J 3$ are near to zero. The sample AC for the estimated model errors is presented in Figure 6(a). It is seen that the residuals of the model are within the $95 \% \mathrm{AC}$ confidence interval. the results indicate that no information losses are detected for the prediction model. Therefore, the 


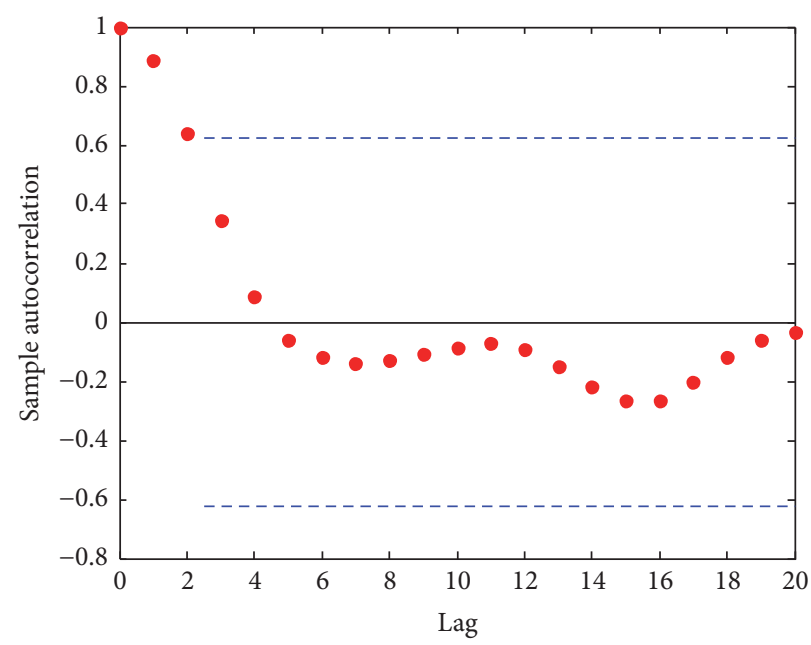

(a)

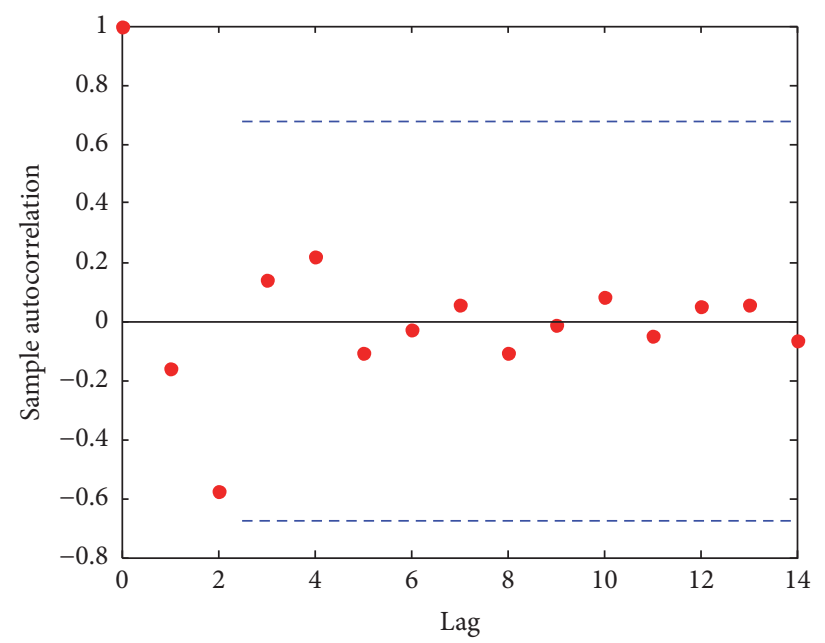

(b)

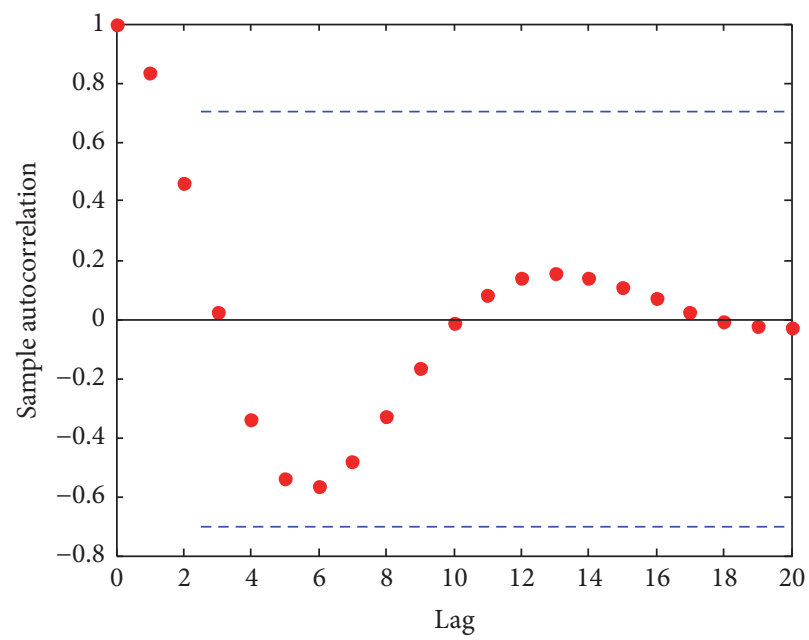

(c)

FIGURE 6: ACF of the models residuals (a) LSSVM, (b) WNN, and (c) ANFIS.

model with wavelet denoise is recommended to be used in the efficient prediction of the behavior of building.

The same condition applied with the LSSVM model is used with the WNN model. The wavelet denoising is applied before model process. Also the numbers of the input and output parameters are three and one, respectively. In the WNN models, the numbers of wavelet neurons, wavelet function, learning rate, weight initiation, and so forth [25] are controlling parameters. As presented previously, the Mexican hat wavelet function is used in this study, while the empirical methods are used to calculate the model parameters. By trying different architectures with different numbers of wavelet neurons, the optimum number of wavelet neurons is identified based on lowest RMSE and MAE. The evaluation of $5,10,25$, and 30 wavelet neurons found that the RMSE for each trail are $1.05 e-2,1.08 e-2,1.08 e-2$, and $1.08 e-$ $2 \mathrm{~g}$, respectively. In this study, the 25 wavelet neurons are selected to predict the building behavior. The dilation and transition properties of the wavelet function make the wavelet network much more dynamic, flexible, robust, and promising methodology for building behavior modeling and prediction than traditional artificial Neural network method.

Based on the values of the $J 1$ and $J 4$, as presented in Table 2, the correlation between the prediction and observation acceleration is high. In addition, the model errors, the values of $J 2$ and $J 3$, are small, with acceptable information losses as shown in Figure 6(b). The results presented in Table 2 and Figures 6(b) and 7(b) show that the WNN is acceptable to use to predict the behavior of building under strong GM.

The same conditions that were presented in the two previous models are applied with the ANFIS model. Wavelet one-delayed only $[5,6]$ is used to compare the two models results. Based on the previous studies $[5,18]$, the number and type of membership function (MF) and time delay of the input are main parameters to design the ANFIS model, while the ANFIS is a special case of the NN [26]. The two, three, and four MF are evaluated with Sigmoid function. It was found that the RMSE for the two, three, and four MF are 


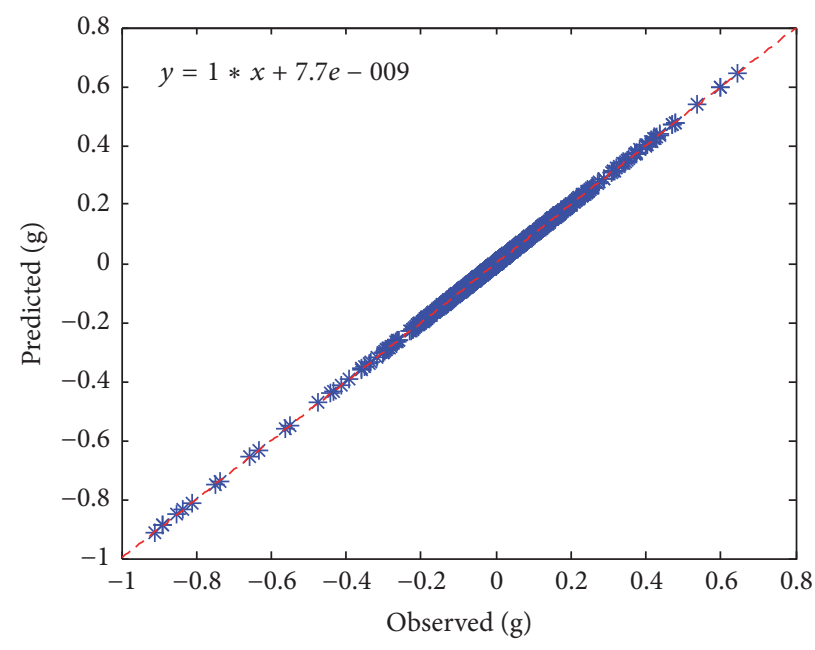

(a)

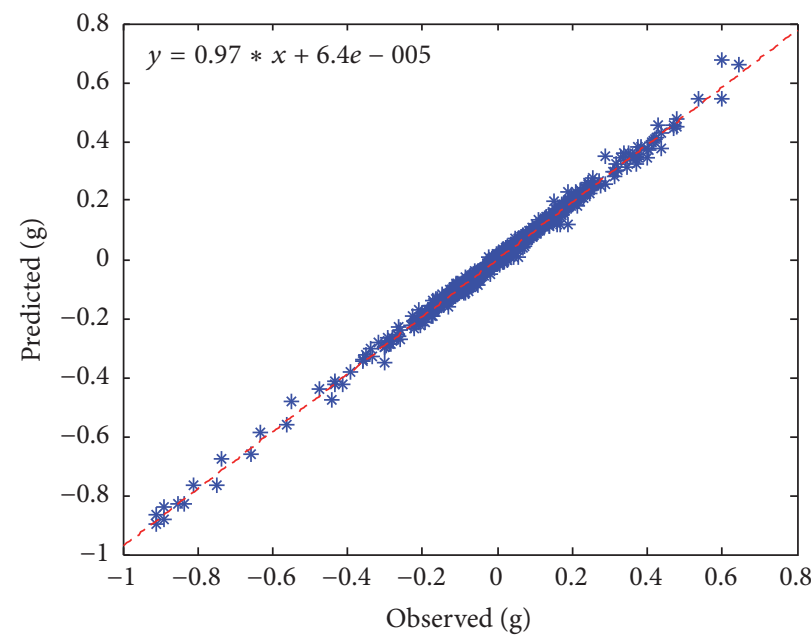

(b)

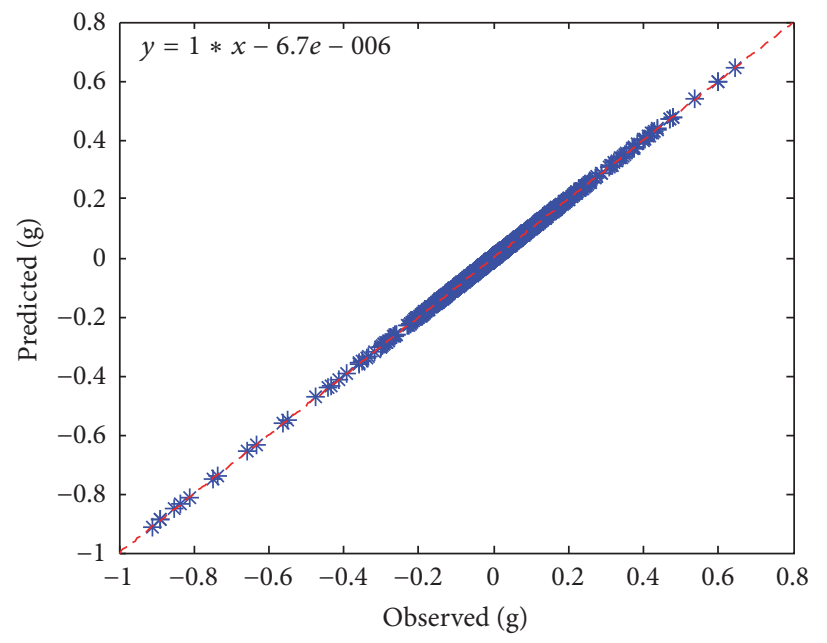

(c)

FIGURE 7: Prediction response of three models with measured GM, (a) LSSVM, (b) WNN, and (c) ANFIS

$1.85 e-5,6.94 e-2$, and $7.70 e-2 \mathrm{~g}$, respectively. Moreover, the Sigmoid, Gaussian and triangle shapes functions are tested with two MF. The results show that the RMSE are $1.85 e-5$, $3.74 e-4$, and $1.28 e-3 \mathrm{~g}$ for the Sigmoid, Gaussian and triangle shapes functions, respectively. Therefore, based on the previous results, the two MF and Sigmoid function are selected in this study to predict the building behavior. In addition, the one- and two-delayed input for the behavior of building is applied. The statistical performances $J 1, J 2$, $J 3$, and $J 4$ for the one-delayed inputs are $0.98,9.94 e-3 \mathrm{~g}$, $2.03 e-2 \mathrm{~g}$, and 99.93 , respectively. Moreover, the two-delayed performance is presented in Table 2. The results of one and two-delayed evaluation show that the two-delayed is better to predict the building behavior. As shown in Table 2 and Figures 6(c) and 7(c), the ANFIS model can be used to detect the building behavior with high quality and best fitting of signal measurement.

Finally, it can be concluded that the developed LSSVM and ANFIS are the best models to detect the building behavior under GM effects. The CPU processing time of the ANFIS model is lower than the LSSVM and the WNN, while the performance analysis of the three models shows that the LSSVM is better. However, the LSSVM and ANFIS models are utilized in a testing stage to detect the better one in the process to predict the building behavior. Seven cases of building responses based on seven GMs' effects with the two models are evaluated as presented in Table 3 . The prediction response is evaluated based on statistical performance analysis of $J 1$ to J4.

The building behavior measurements and the LSSVM and ANFIS models predictions for the GMs' LA 20 and 27 are presented in Figure 9. Moreover, the AC function for the LSSVM and ANFIS models errors is evaluated. From Table 3 , it is seen that the $J 1$ and $J 4$ parameters are the same for the two models, thus meaning that the correlation between the observations and predictions response for each model is high. Also, it is observed that J2 and J3 for the LSSVM model are smaller than those for the ANFIS model. 


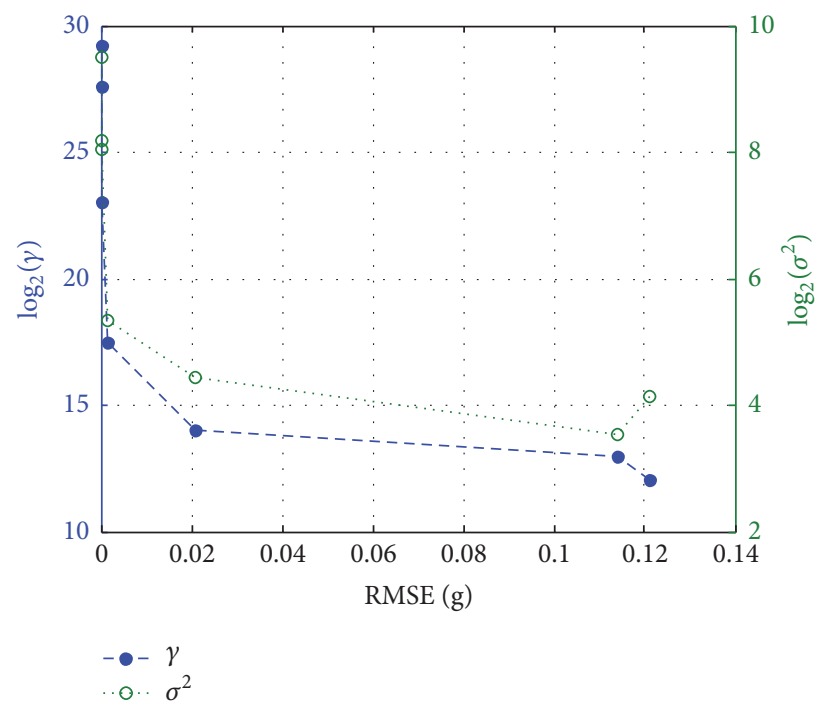

(a)

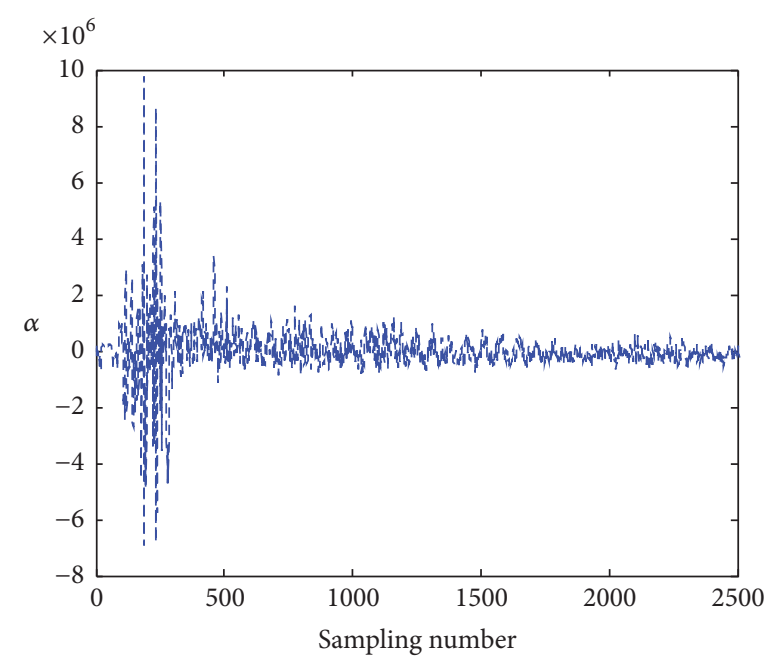

(b)

FIGURE 8: (a) RMSE for RBF kernel trails and (b) values of $\alpha$ for building behavior prediction.

TABLE 3: Validation analysis of the LSSVM and ANFIS model.

\begin{tabular}{lcccccccc}
\hline GM & \multicolumn{3}{c}{$J 1$} & \multicolumn{2}{c}{$J 2(\mathrm{~g})$} & \multicolumn{2}{c}{$J 3(\mathrm{~g})$} & \multicolumn{2}{c}{$J 4(\%)$} \\
& LSSVM & ANFIS & LSSVM & ANFIS & LSSVM & ANFIS & LSSVM & ANFIS \\
\hline LA4 & 0.99 & 0.99 & $2.21 e-9$ & $5.82 e-6$ & $4.73 e-9$ & $1.59 e-5$ & 99.99 \\
LA8 & 0.99 & 0.99 & $1.88 e-7$ & $8.50 e-6$ & $3.26 e-7$ & $1.92 e-5$ & 99.99 & 99.99 \\
LA13 & 0.99 & 0.99 & $2.61 e-8$ & $8.26 e-6$ & $4.21 e-8$ & $1.82 e-5$ & 99.99 & 99.99 \\
LA20 & 0.99 & 0.99 & $2.73 e-8$ & $8.78 e-6$ & $4.67 e-8$ & $1.99 e-5$ & 99.99 & 99.99 \\
LA23 & 0.99 & 0.99 & $1.53 e-9$ & $8.55 e-6$ & $2.67 e-9$ & $1.89 e-5$ & 99.99 & 99.99 \\
LA27 & 0.99 & 0.99 & $1.13 e-8$ & $1.48 e-5$ & $1.42 e-8$ & $2.76 e-5$ & 99.99 & 99.99 \\
LA30 & 0.99 & 0.99 & $3.27 e-8$ & $1.75 e-5$ & $4.55 e-8$ & $3.11 e-5$ & 99.99 & 99.99 \\
\hline
\end{tabular}

The results presented in Figure 9 show that the two models prediction signals are very close to the observed building behavior. Moreover, The AC for the errors of the two models is within $95 \%$ confidence interval indicating no information loss was observed for each model. Also, the AC values for the LSSVM model are smaller than that for the ANFIS model indicating that the LSSVM model is better than ANFIS model to predict the behavior of buildings subjected by LRB isolator system under strong GMs' effects.

From the previous results for the training and testing stages, it can be concluded that the three developed models (LSSVM, WNN, and ANFIS) can be used to predict the behavior of buildings. It is recommended that the LSSVM model can be used with lower sampling numbers of observation data, while it takes longer CPU processing time. Finally, based on the results obtained from Table 3 and Figure 9, it is concluded that the two models can be used to predict the behavior of buildings with LRB isolator under strong GMs' effects. The statistical performance shows that the LSSVM is better than ANFIS for use in the presented case in this paper. Also, the ANFIS model is recommended with higher numbers of sampling data measurements.

\section{Conclusions}

In this study, the seismic response of a simulation of the CBF steel building with LRB isolation is predicted based on a development of advanced soft computing calculation methods, which are LSSVM, WNN, and ANFIS with wavelet denoising. Eight sets of near-field ground motion records are used to design the prediction models. Two-delayed structure response is used with seismic effect to design the prediction model.

The results of the training and testing stages concluded that the three models can be used to detect the behavior of buildings with high performance based on statistical evaluation of the three models. Moreover, the performances of the developed LSSVM and ANFIS models are better than the WNN model. The ANFIS model has the advantage of being a quick tool for predicting the behavior of buildings while the LSSVM model has the advantage of being the accurate model. The training and testing evaluation results showed that the developed LSSVM with wavelet denoising is very effective in estimating the nonlinear behavior of $\mathrm{CBF}$ steel building with LRB isolation under a variety of high impact ground motions. 

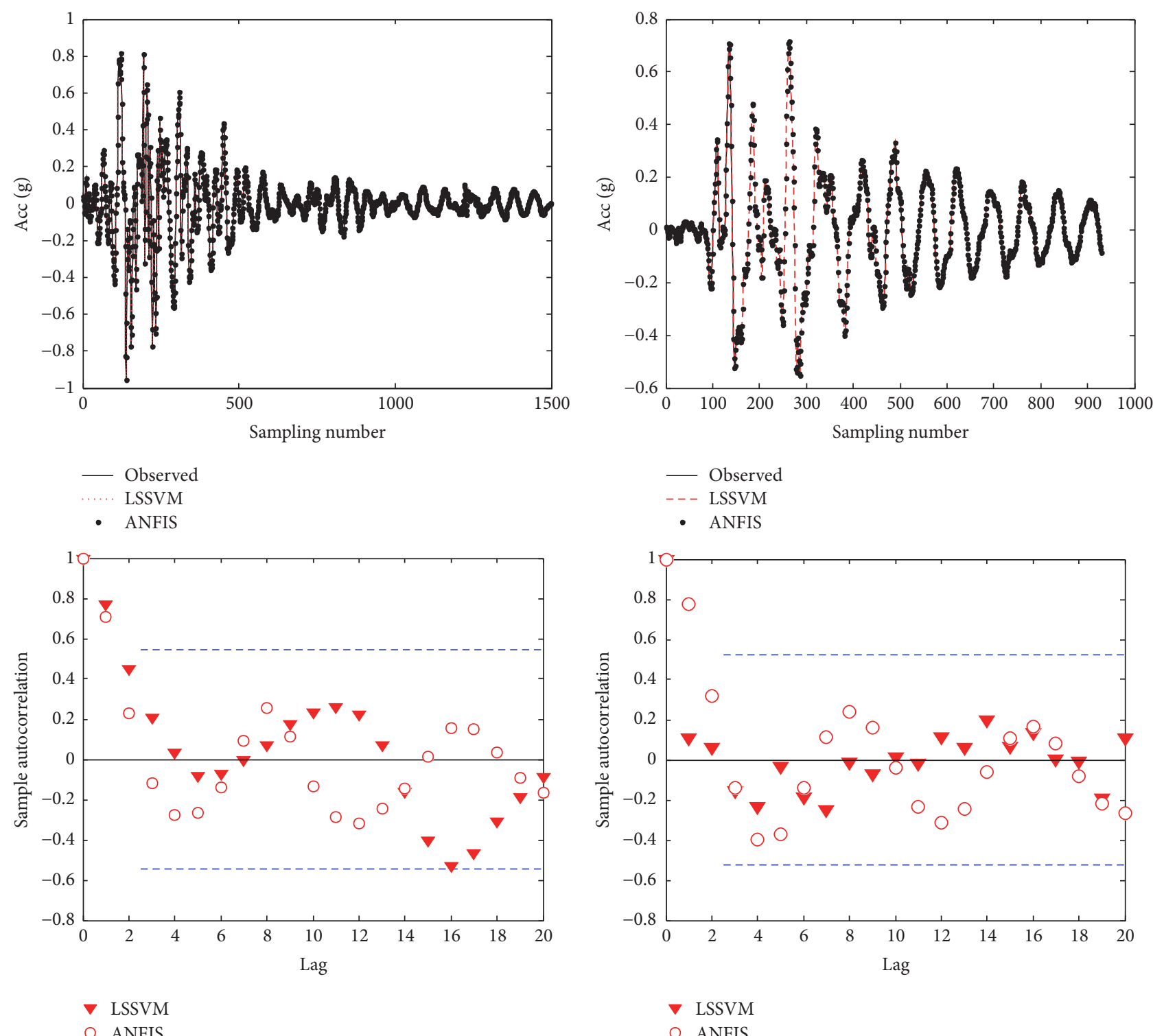

(a)

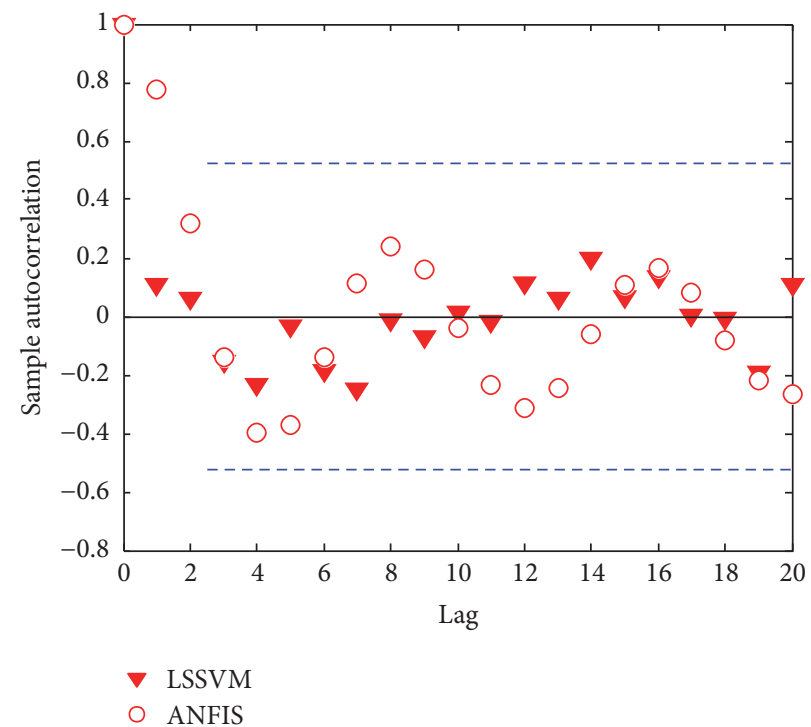

(b)

FIGURE 9: Prediction response and ACF of model for the response of building with GM, (a) LA20 and (b) LA27.

\section{Competing Interests}

The authors declare that there is no conflict of interests regarding the publication of this paper.

\section{Acknowledgments}

This research was supported by a Grant (15TBIP-C09300101) from Support for Infrastructure and transportation technology commercialization Program funded by Ministry of Land, Infrastructure and Transport of Korean government. The authors gratefully acknowledge this support.

\section{References}

[1] J. Seo and J. W. Hu, "Seismic response and performance evaluation of self-centering LRB isolators installed on the CBF building under NF ground motions," Sustainability (Switzerland), vol. 8, no. 2, 2016.

[2] J. Hu, "Seismic Performance Evaluations and Analyses for Composite Moment Frames with Smart SMA PR-CFT Connections," 2008.

[3] M. Shinozuka, S. R. Chaudhuri, and S. K. Mishra, "ShapeMemory-Alloy supplemented Lead Rubber Bearing (SMALRB) for seismic isolation," Probabilistic Engineering Mechanics, vol. 41, pp. 34-45, 2015.

[4] A. Hossain, A. Rteil, and M. S. Alam, "Seismic performance of concrete buildings reinforced with shape memory alloy rebars," in Proceedings of the Annual Conference of the Canadian Society for Civil Engineering, vol. 3, May 2015.

[5] K. S. Arsava, Y. Kim, T. El-Korchi, and H. S. Park, "Nonlinear system identification of smart structures under high impact 
loads," Smart Materials and Structures, vol. 22, no. 5, Article ID 055008, 2013.

[6] R. Mitchell, Y. Kim, and T. El-Korchi, "System identification of smart structures using a wavelet neuro-fuzzy model," Smart Materials and Structures, vol. 21, no. 11, Article ID 115009, 2012.

[7] R. B. Salic, M. A. Garevski, and Z. V. Milutinovic, "Response of lead-rubber bearing isolated structure," in Proceedings of the 14th World Conference on Earthquake Engineering (WCEE '08), Beijing, China, October 2008.

[8] M. Ismail, J. Rodellar, and J. R. Casas, "Seismic behavior of RNC-isolated bridges: a comparative study under nearfault, long-period, and pulse-like ground motions," Advances in Materials Science and Engineering, vol. 2016, Article ID 1897045, 18 pages, 2016.

[9] H. Sohn, C. R. Farrar, F. Hemez, and J. Czarnecki, "A review of structural health monitoring literature 1996-2001," in Proceedings of the 3rd World Conference on Structural Control, pp. 1-7, December 2002.

[10] M. R. Kaloop and J. W. Hu, "Damage identification and performance assessment of regular and irregular buildings using wavelet transform energy," Advances in Materials Science and Engineering, vol. 2016, Article ID 6027812, 11 pages, 2016.

[11] M. R. Kaloop, J. W. Hu, M. A. Sayed, and J. Seong, "Structural performance assessment based on statistical and wavelet analysis of acceleration measurements of a building during an earthquake," Shock and Vibration, vol. 2016, Article ID 8902727, 13 pages, 2016.

[12] F. McKenna, "OpenSees: a framework for earthquake engineering simulation," Computing in Science and Engineering, vol. 13, no. 4, pp. 58-66, 2011.

[13] P. Samui, D. Kim, and B. G. Aiyer, "Pullout capacity of small ground anchor: a least square support vector machine approach," Journal of Zhejiang University SCIENCE A, vol. 16, no. 4, pp. 295-301, 2015.

[14] R. Mitchell, A WANFIS Model for Use in System Identification and Structural Control of Civil Engineering Structures, Worcester Poytechnic Institute, 2012.

[15] K. S. Arsava, Y. Kim, K. H. Kim, and B.-S. Shin, "Smart fuzzy control of reinforced concrete structures excited by collisiontype forces," Expert Systems with Applications, vol. 42, no. 21, pp. 7929-7941, 2015.

[16] J. W. Hu and M. R. Kaloop, "Single input-single output identification thermal response model of bridge using nonlinear ARX with wavelet networks," Journal of Mechanical Science and Technology, vol. 29, no. 7, pp. 2817-2826, 2015.

[17] S. Arangio and F. Bontempi, "Bayesian neural networks for damage identification of a cable-stayed bridge," in Proceedings of the 6th International Conference on Bridge Maintenance, Safety and Management (IABMAS '12), pp. 2260-2266, CRC Press, Stresa, Italy, July 2012.

[18] M. Kaloop, J. Hu, and Y. Bigdeli, "Identification of the response of a controlled building structure subjected to seismic load by using nonlinear system models," Applied Sciences, vol. 6, no. 10, 2016.

[19] G. F. Sirca Jr. and H. Adeli, "System identification in structural engineering," Scientia Iranica, vol. 19, no. 6, pp. 1355-1364, 2012.

[20] J. A. K. Suykens and J. Vandewalle, "Least squares support vector machine classifiers," Neural Processing Letters, vol. 9, no. 3, pp. 293-300, 1999.

[21] P. Samui and D. P. Kothari, "Utilization of a Least Square Support Vector Machine (LSSVM) for slope stability analysis," Scientia Iranica, vol. 18, no. 1, pp. 53-58, 2011.
[22] O. Kisi, "Modeling discharge-suspended sediment relationship using least square support vector machine," Journal of Hydrology, vol. 456-457, pp. 110-120, 2012.

[23] B. B. Ekici, "A least squares support vector machine model for prediction of the next day solar insolation for effective use of PV systems," Measurement, vol. 50, no. 1, pp. 255-262, 2014.

[24] D. Veitch, Wavelet Neural Networks and their application in the study of dynamical systems [M.S. thesis], Univeristy of York, 2005.

[25] M. El-Diasty and S. Al-Harbi, "Development of wavelet network model for accurate water levels prediction with meteorological effects," Applied Ocean Research, vol. 53, pp. 228-235, 2015.

[26] J.-S. R. Jang, "ANFIS: adaptive-network-based fuzzy inference system," IEEE Transactions on Systems, Man and Cybernetics, vol. 23, no. 3, pp. 665-685, 1993.

[27] I. Mansouri, A. Gholampour, O. Kisi, and T. Ozbakkaloglu, "Evaluation of peak and residual conditions of actively confined concrete using neuro-fuzzy and neural computing techniques," Neural Computing and Applications, pp. 1-16, 2016.

[28] M. Eldessouki and M. Hassan, "Adaptive neuro-fuzzy system for quantitative evaluation of woven fabrics' pilling resistance," Expert Systems with Applications, vol. 42, no. 4, pp. 2098-2113, 2015.

[29] G. Landeras, J. J. López, O. Kisi, and J. Shiri, “Comparison of Gene Expression Programming with neuro-fuzzy and neural network computing techniques in estimating daily incoming solar radiation in the Basque Country (Northern Spain)," Energy Conversion and Management, vol. 62, pp. 1-13, 2012.

[30] M. R. Kaloop, J. W. Hu, and M. A. Sayed, "Bridge performance assessment based on an adaptive neuro-fuzzy inference system with wavelet filter for the GPS measurements," ISPRS International Journal of Geo-Information, vol. 4, no. 4, pp. 2339-2361, 2015.

[31] J. W. Hu, "Design motivation, mechanical modeling and nonlinear analysis of composite PR moment frames with smart SMA connection systems," Advanced Steel Construction, vol. 9, no. 4, pp. 334-349, 2013.

[32] J. W. Hu and M. Noh, "Seismic response and evaluation of SDOF self-centering friction damping braces subjected to several earthquake ground motions," Advances in Materials Science and Engineering, vol. 2015, Article ID 397273, 17 pages, 2015.

[33] J. W. Hu, "Response of seismically isolated steel frame buildings with sustainable lead-rubber bearing (LRB) isolator devices subjected to near-fault (NF) ground motions," Sustainability, vol. 7, no. 1, pp. 111-137, 2015.

[34] American Institute of Steel Construction, Steel Construction Manual, AISC, 2005. 

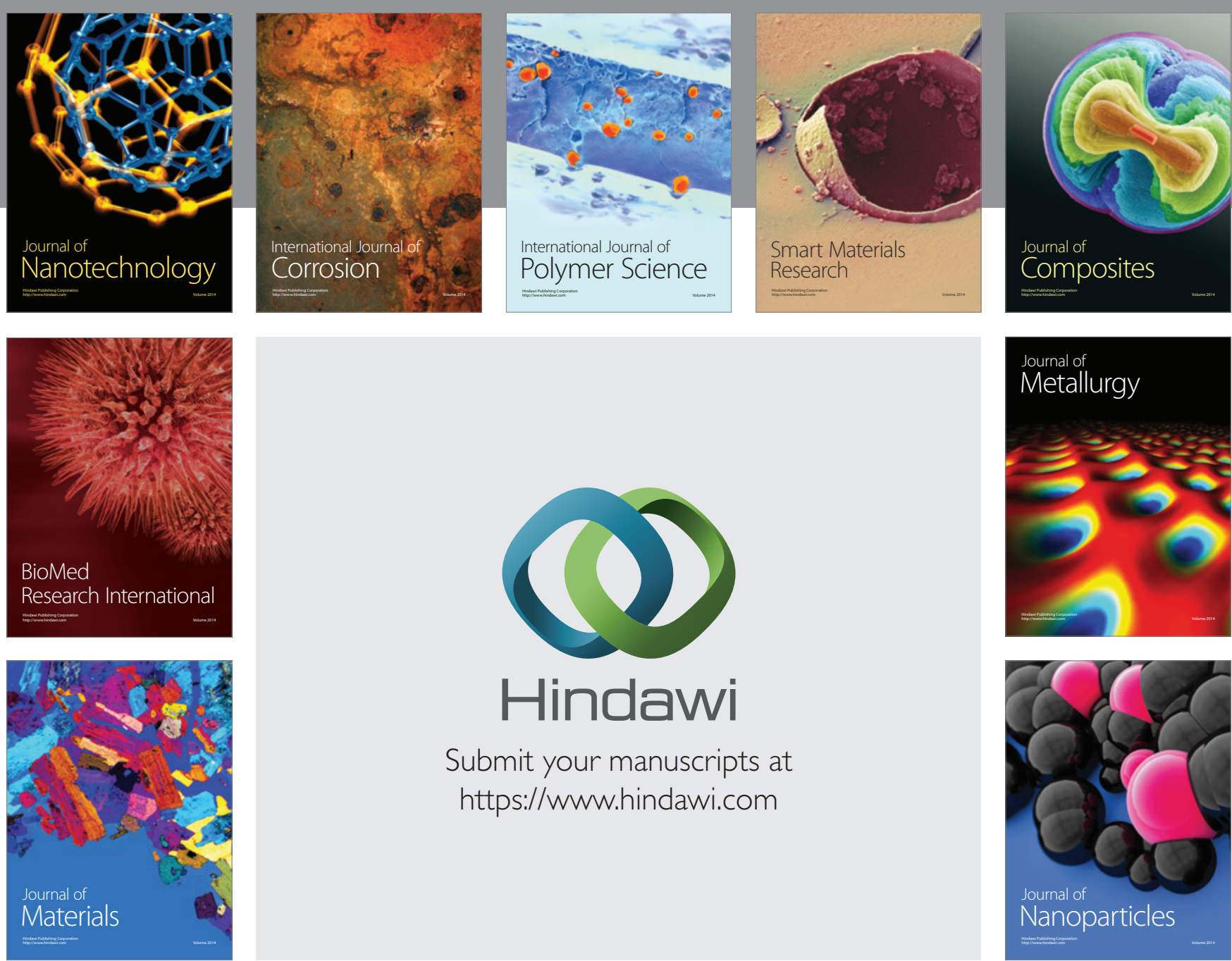

\section{Hindawi}

Submit your manuscripts at

https://www.hindawi.com

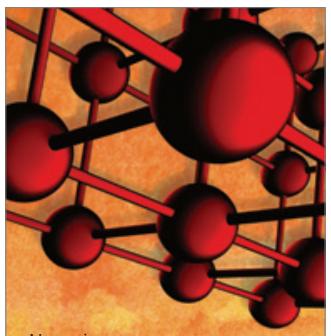

Materials Science and Engineering
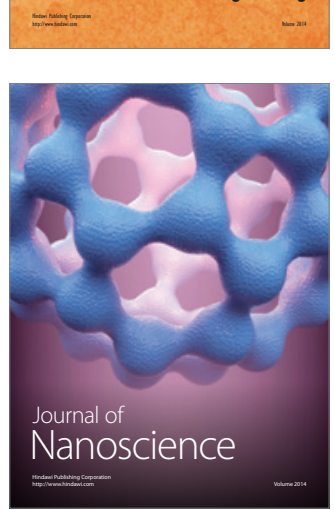
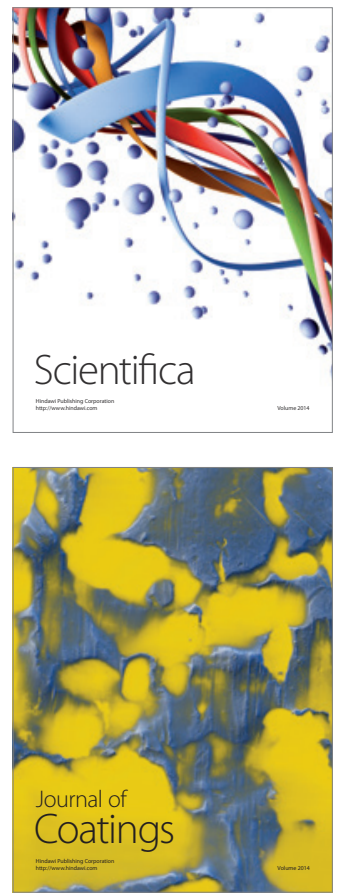
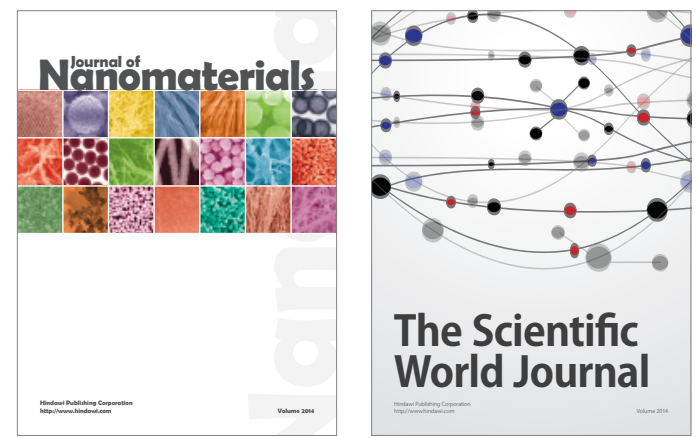

The Scientific World Journal
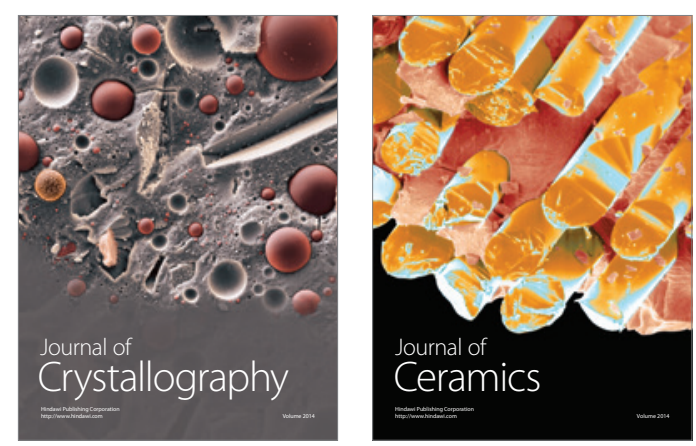
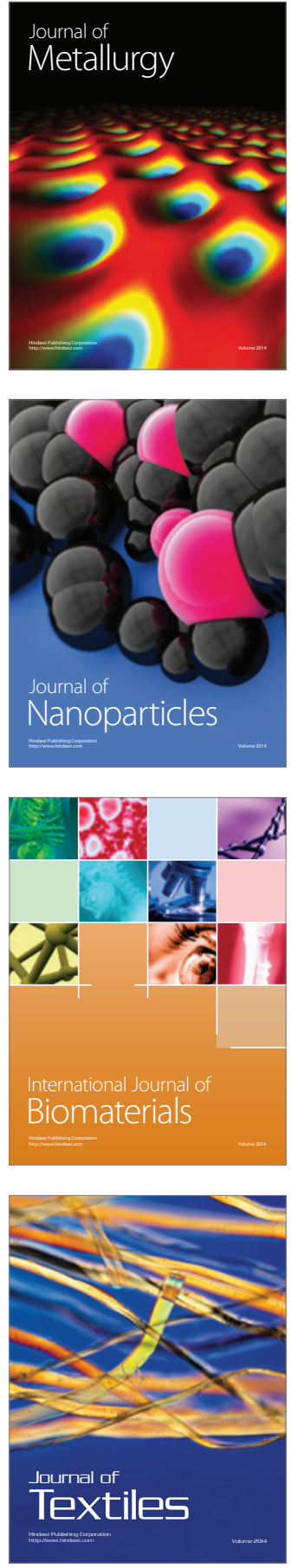